
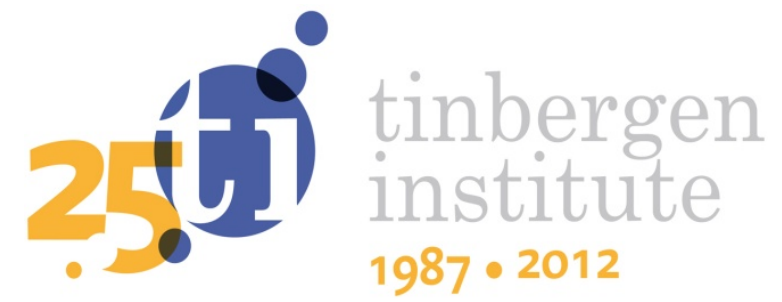

\title{
Deterministic versus Random Utility: Implied Patterns of Vertical Product Differentiation in a Multi-Product Monopoly
}

\section{Christiaan Behrens"}

Mark Lijesen

Eric Pels*

Erik Verhoef*

Department of Spatial Economics, Faculty of Economics and Business Administration, VU University of Amsterdam.

* Tinbergen Institute. 
Tinbergen Institute is the graduate school and research institute in economics of Erasmus University Rotterdam, the University of Amsterdam and VU University Amsterdam.

More TI discussion papers can be downloaded at http://www.tinbergen.nl

Tinbergen Institute has two locations:

Tinbergen Institute Amsterdam

Gustav Mahlerplein 117

1082 MS Amsterdam

The Netherlands

Tel.: +31(0)205251600

Tinbergen Institute Rotterdam

Burg. Oudlaan 50

3062 PA Rotterdam

The Netherlands

Tel.: +31(0)10 4088900

Fax: $+31(0) 104089031$

Duisenberg school of finance is a collaboration of the Dutch financial sector and universities, with the ambition to support innovative research and offer top quality academic education in core areas of finance.

DSF research papers can be downloaded at: http://www.dsf.nl/

Duisenberg school of finance

Gustav Mahlerplein 117

1082 MS Amsterdam

The Netherlands

Tel.: +31(0)20 5258579 
Deterministic versus random utility: Implied patterns of vertical product differentiation in a multiproduct monopoly

Christiaan Behrens ${ }^{1 *}$, Mark Lijesen, Eric Pels* ${ }^{*}$ Erik Verhoef*

Dept. of Spatial Economics, VU University Amsterdam.

*Tinbergen Institute, Amsterdam/Rotterdam.

\section{Abstract}

In this article we study patterns of vertical product differentiation in a multi-product monopoly using a random utility model. Prior research shows that applying such a model in a multi-product setting implies symmetric patterns of product differentiation in which all product variants of a single firm have the same characteristics. Assuming that preferences differ across consumers and allowing for unobserved demand heterogeneity, we numerically show the existence of asymmetric, fully differentiated, patterns of vertical product differentiation in which the monopolist maximises profits by setting prices and qualities. In particular, we show that the patterns of vertical product differentiation depend crucially on the level of unobserved demand heterogeneity and the observed dispersion of willingness to pay for quality. Only if unobserved demand heterogeneity is small relative to the observed dispersion, asymmetric, fully differentiated, equilibriums exist. Furthermore, we find in our model that the level of unobserved heterogeneity and the dispersion of willingness to pay for quality do not affect the relative welfare efficiency of the monopolist.

Keywords: Vertical product differentiation, market segmentation, multi-product monopoly, random utility models

\footnotetext{
${ }^{1}$ We gratefully acknowledge The Netherlands Organization for Scientific Research (NWO) for financial support (Grant number 400-08-012). Also the financial support from the ERC (Advanced Grant OPTION \#246969) for the research of Erik Verhoef is gratefully acknowledged.
} 


\section{Introduction}

Vertical product differentiation is observed in many industries. For example, in aviation one can find a high degree of product differentiation both between airlines as well as between the products offered by a single airline, but other examples are of course easily found. The desire to understand the economic motives of multi-product firms applying vertical product differentiation resulted into a number of studies in which these firms are assumed to maximise profits using two decision variables, typically prices and qualities (see e.g. Mussa and Rosen (1978), Champsaur and Rochet (1989), Bonnisseau and Lahmandi-Ayed (2006), and Cheng et al. (2011)).

The seminal article by Mussa and Rosen (1978), and successive studies by others, assume that the willingness to pay for quality differs across consumers and that consumer demand is deterministic. In this article, we study the patterns of vertical product differentiation in a multi-product monopoly using a random utility framework. The random utility framework is more general and represents the more realistic case in which the firm, or the researcher, cannot predict, or monitor, consumer preferences completely. Furthermore, the random utility framework is frequently used in empirical analyses regarding multi-product industries. ${ }^{2}$

A key question regarding vertical product differentiation is whether the predicted equilibrium patterns are symmetric, in the sense that prices and qualities of all product variants supplied by a single firm are equal, or not. Mussa and Rosen (1978) and Cheng et al. (2011) show that for deterministic models fully differentiated equilibrium patterns exist in case of a monopoly and duopoly. In sharp contrast, Anderson et al. (1992) mention the so-called constant mark-up property as a result from the random utility model,

\footnotetext{
${ }^{2}$ Seminal empirical contributions are made by Berry (1994) and Berry et al. (1995), see for a recent overview on this literature Crawford (2012).
} 
implying symmetric patterns of vertical product differentiation. ${ }^{3}$ We are not aware of any attempt to show the existence of non-symmetric equilibrium patterns of vertical product differentiation within a random utility framework. Therefore, in this article we study the question of whether, and under which conditions, the random utility framework is applicable in modelling the, mainly non-symmetric, patterns of vertical product differentiation, as observed in multi-product industries.

Based on a theoretical model, which is closely related to the model used by Mussa and Rosen (1978), we study the relationship between the level of the observed indirect utility on the one hand, as determined by prices, qualities, and the dispersion in the willingness to pay for quality, and unobserved utility on the other. The non-linear nature of the random utility framework prevents insightful analytical results from being available, and we perform a numerical analysis from which we conclude that the monopolist supplies vertically differentiated product variants if the level of unobserved heterogeneity is relatively small compared with the observed dispersion in willingness to pay for quality across consumers.

Section 2 introduces the basic model of vertical product differentiation. In Section 3 we discuss the patterns of vertical product differentiation in case the monopolist faces deterministic heterogeneous demand. In Section 4 we relax the assumption of deterministic demand by introducing a random utility framework. We discuss in detail the resulting equilibrium patterns of vertical product differentiation in this case, and look at the welfare implications. Section 5 provides a discussion and conclusion.

\footnotetext{
${ }^{3}$ In their study of multi-product firms, Anderson and de Palma (1992a) are particularly interested in the number of product variants per firm and not in the implied patterns of product differentiation. They study quality choice, multi-product firms, and observed demand heterogeneity separately. Our article shows that the absolute mark-up property is partly due to the nature of the discrete choice model and partly due to the specific set of assumptions applied by Anderson and de Palma. They relax this specific set of assumptions in the context of horizontal product differentiation, and not in the context of vertical product differentiation.
} 


\section{Background}

We assume that each consumer decides to purchase one variant out of all product variants, or not to buy at all. ${ }^{4}$ The indirect utility of consumer $t$ is as follows:

$$
V_{t}=\left\{\begin{array}{ll}
y-\alpha p_{i}+\theta_{t} q_{i} & \text { if consumert purchasesvariant } i \\
y & \text { otherwise }
\end{array},\right.
$$

product variant $i$ is characterised by its price, $p_{i}$, and quality, $q_{i}$. The generic parameter $y$ captures the base utility from other goods, while the generic coefficient $\alpha$ captures the marginal utility of income, and $\theta_{t}$ represents the consumer specific marginal utility derived from quality. Therefore, consumers are homogenous with respect to their marginal utility of income. However, the implied willingness to pay for a unit increase in quality, $\theta_{t} / \alpha$, differs across consumers following a uniformly distribution over the interval $[\underline{\theta}, \bar{\theta}]$, with density normalised to 1 .

Consumers select themselves in product variants according to their willingness to pay for quality. Consumers with a relatively high $\theta$ are willing to pay more for quality and therefore select themselves in product variants with relatively higher qualities and prices when prices and qualities vary over variants that are supplied in equilibrium.

The utility function as depicted in Eq. (1) has no random terms and is deterministic; the utility of consumers is fully explained by prices and qualities of the supplied product variants, the consumer sensitivities regarding these variables, and the base utility derived from other goods $y$. This model is

\footnotetext{
${ }^{4}$ Applying Roy's identity to the first line of Eq. (1) gives $x_{i}=\left(\partial V_{i} / \partial p_{i}\right) /\left(\partial V_{i} / \partial y\right)=1$, therefore conditional demand is constant and equals one.
} 
applied throughout the literature by, amongst others, Mussa and Rosen (1978), Gabszewicz et al. (1986), Bonnisseau and Lahmandi-Ayed (2006), and Cheng et al. (2011).

Producing quality is costly. We assume that the costs of quality improvement per unit of output become increasingly costly when quality increases. The unit costs of quality are strictly convex:

$$
c\left(q_{i}\right)=\left(a q_{i}+b q_{i}^{2}\right)
$$

We assume $a \geq 0, b>0, c^{\prime}\left(q_{i}\right)>0$ and $c^{\prime \prime}\left(q_{i}\right)>0$ for all $q_{i}$. The cost function and linear specification of utility guarantee an interior solution with respect to quality setting. ${ }^{5}$ The optimal quality level for a given $\theta_{t}$ is determined by setting marginal costs of quality improvement, $\left(a+2 b q_{i}\right)$, equal to the willingness to pay for quality, $\theta_{t} / \alpha{ }^{6}$

By adding a random error term, $\varepsilon$, to the indirect utility function we introduce unobserved heterogeneity:

$$
V_{t}= \begin{cases}y-\alpha p_{i}+\theta_{t} q_{i}+\varepsilon_{i t} & \text { if consumert purchasesvariant } i \\ y+\varepsilon_{y t} & \text { otherwise }\end{cases}
$$

\footnotetext{
${ }^{5}$ This general formulation is applied by Mussa and Rosen (1978). By assuming $a=0$ and $b=1 / 2$ we arrive at the specification applied by Cheng et al. (2011). Note that the supply of a product variant with infinite quality is ruled out to be profitable using these utility and cost functions.

${ }^{6}$ From this we can directly derive the quality the monopolist would provide in case everyone would have the same willingness to pay for quality: $q_{i}^{*}=((\theta / \alpha)-a) / 2 b$. Note that this coincides with the social optimal quality level, but the price setting differs between the monopoly outcome and social optimum.
} 
Assuming that the random error term is i.i.d. Gumbel distributed we may write the expected demand functions as usual logit probabilities. One of the properties of the Gumbel distribution is that the variance equals $\mu^{2}\left(\pi^{2} / 6\right)$. The importance of the unobserved error term compared with the observed prices and qualities increases with this variance. The term in brackets is just a constant, however, the parameter $\mu$, the so-called scale parameter, needs to be (empirically) determined (see e.g. Ben-Akiva and Lerman, 1985). We show in Section 4 that the value of the scale parameter, and therefore the relative level of unobserved utility components, plays an important role in the implied pattern of product differentiation.

The model as described in Eq. (1) and Eq. (2) has been used to study deterministic demand heterogeneity in single-product duopolistic markets. Using backward induction, a unique Cournot-Nash equilibrium in prices and qualities can be found. In the first stage, firms set their quality level, and in the second stage they set their prices accordingly. The standard textbook results show that equilibrium profits rise in quality differences between the two variants. Therefore there is a clear incentive to get a maximum differentiation between the two variants of both firms (see e.g. Tirole (1988)). ${ }^{7}$ The principle of maximum differentiation holds, even if costs of quality are ignored and a symmetric duopoly is assumed. However, the observed heterogeneity in demand needs to be large enough, i.e. $\bar{\theta}>2 \underline{\theta}$, otherwise the interior optimal price of the low-quality variant becomes negative, so that one firm will cease to be active (Anderson et al., 1992, page 309).

\footnotetext{
7 The principle of maximum differentiation also applies to Hotelling type of models of horizontal product differentiation. Both in horizontal and vertical product differentiation models, firms differentiate their products (in space or characteristic space) in order to segment the market and to increase their market power and thereby their mark-up and profits. See Anderson et al. (1992) for a detailed exposition on the models of horizontal and vertical product differentiation.
} 
Besides studying vertical product differentiation for single-product firms, the deterministic model has been extended to multi-product firms. Mussa and Rosen (1978) and Gabszewicz et al. (1986) show that the monopolist maximises its profits by supplying multiple product variants with vertically differentiated qualities.

The various studies into multi-product duopolists produce different results. Champsaur and Rochet (1989) and Bonnisseau and Lahmandi-Ayed (2006) find that the profit-optimising duopolist supplies just a single product variant. Cheng et al. (2011) argue that the assumption of perfectly inelastic demand may explain the results found by Champsaur and Rochet (1989) and Bonnisseau and Lahmandi-Ayed (2006). In our model the demand for products conditional on buying a product is perfectly inelastic, however, the unconditional demand is elastic because consumers can choose not to buy and obtain their base utility, $y$, as shown in the last line of both Eq (1) and Eq (3).

We conclude that deterministic heterogeneity results in asymmetric patterns of vertical product differentiation for monopolies as well as duopolies. We are not aware of any attempt to reproduce the results of Mussa and Rosen (1978) using the more general random utility framework. Anderson et al. (1992) are the first to integrate the discrete choice model into traditional models of vertical product differentiation, however their results only show symmetric equilibriums. In the remainder, we first provide more details of the deterministic model in order to compare this model with the random utility model in section 4 . 


\section{Multi-product monopoly facing deterministic heterogeneous demand}

We follow closely the model by Mussa and Rosen (1978) and Cheng et al. (2011). ${ }^{8}$ The monopolist supplies $n$ product variants are supplied and the variants are ranked in quality from $q_{1}, \ldots, q_{n}$, with $q_{1}$ representing the highest quality variant and $q_{n}$ the lowest quality variant. ${ }^{9}$ The marginal consumer $t$ is defined to be the one with that $\theta_{i}$ for which she is indifferent between choosing two successive product variants, $V_{i, t}=V_{i+1, t}$, or choosing between the lowest quality variant and not buying at all, $V_{n+1}=y$. Solving for $\theta_{i}$ yields for every pair of variants $i$ and $i+1$ :

$$
\theta_{i}= \begin{cases}\frac{\alpha\left(p_{i}-p_{i+1}\right)}{q_{i}-q_{i+1}} & \text { for } i=1, \ldots, n-1 \\ \max \left\{\frac{\alpha p_{i}}{q_{i}}, \underline{\theta}\right\} & \text { for } i=n\end{cases}
$$

Because every consumer buys the product variant which maximises her utility or no variant at all, the demand for each product variant equals:

$$
x_{i}= \begin{cases}\left(\bar{\theta}-\theta_{i}\right) \bar{\theta} & \text { for } i=1 \\ \left(\theta_{i-1}-\theta_{i}\right) \bar{\theta} & \text { for } i=2, \ldots, n\end{cases}
$$

\footnotetext{
${ }^{8}$ Without loss of generality we measure quality linearly in the utility function and in a strictly convex manner in the cost function. It is also possible to have costs linear in quality and utility strictly concave in quality (Anderson et al., 1992). Furthermore, we could also adopt a negative index for quality and interpret this index as the number of restrictions of the product, for example the number of restrictions on a ticket. This measure has the benefit of practical applicability in the afore mentioned transport markets. Define $q_{i}=\phi-r_{i}$, with $\phi$ indicating the maximum number of restrictions on the lowest quality product variant possible. For example, the lowest available air fares in the aviation industry have more restrictions, such as a required minimum stay or inclusion of a Saturday night, compared with more expensive air fares for the same flight. Both interpretations of quality do not alter the insights regarding vertical product differentiation as discussed in this article.

${ }^{9}$ The number of product variants $n$ may be assumed to be exogenously given or, alternatively, endogenously determined.
} 
In line with Eq. (5), the demand for the outside alternative, $x_{\text {out }}$ equals $\left(\theta_{n}-\underline{\theta}\right) / \bar{\theta}$. Figure 1 illustrates the above results for an arbitrary pair of prices and qualities of two product variants, assuming $p_{1}>p_{2}$ and $q_{1}>q_{2}$, and an arbitrarily level of basic utility from other goods. The figure shows the willingness to pay for quality, by assuming $\alpha=1$, for two marginal consumers and the resulting demand for the two product variants. Obviously, not the whole market is covered by the monopolist, because consumers with a willingness to pay between $\underline{\theta}$ and $\theta_{2}$ can attain a higher level of utility by not buying the product at all.

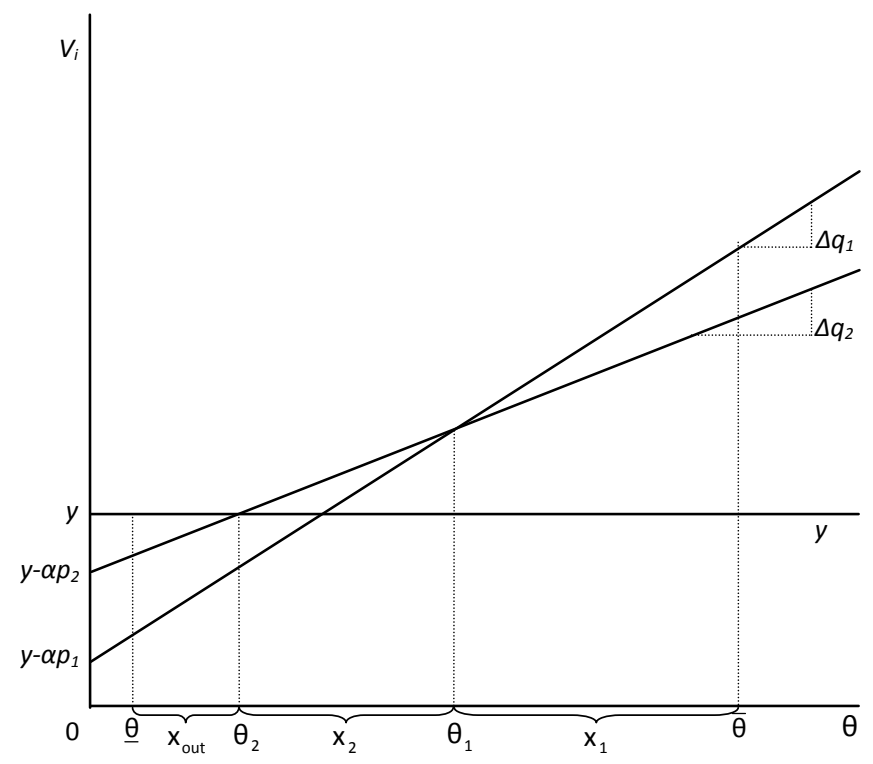

Figure 1 Utility, marginal consumers and resulting demand for two product variants.

In order to model the pattern of product differentiation, and the equilibrium prices and qualities as used in Figure 1, we need to include firm behaviour in the model. The monopolist maximises profits by setting prices and qualities for each product variant $i$. Total profits are equal to the summation over all variants 
of the price minus the costs for quality times the demand for the particular variant. Assuming $a=0$ and $b=1 / 2$, the profit functions yields ${ }^{10}$ :

$$
\pi_{m}=\sum_{i=1}^{n}\left(p_{i}-\frac{q_{i}^{2}}{2}\right) x_{i} .
$$

The order in which the monopolist sets its product specific qualities and prices does not alter the equilibrium outcomes. In fact, for a monopolist the sequential equilibrium is equal to the simultaneous equilibrium by definition. However, we choose to disentangle the maximisation problem into two steps for reasons of clarity and exposition. We formulate a quality-then-price equilibrium and apply backward induction. We define the first-order conditions with respect to prices of the profit function and solve for the equilibrium prices:

$$
p_{i}^{*}\left(q_{i}\right)=\frac{q_{i}}{4 \alpha}\left(\alpha q_{i}+2 \bar{\theta}\right)
$$

Eq. (7) clearly shows that the equilibrium price for each variant has an equal expression for all the product variants, and that the equilibrium price is an increasing function of the quality of that variant. After substituting the expressions of Eq. (7) into the profit function, Eq. (6), we define the first-order conditions with respect to quality, and solve for the equilibrium qualities:

$$
q_{i}^{*}=\frac{2 \bar{\theta}}{\alpha(1+2 n)}(n-i+1)
$$

\footnotetext{
${ }^{10}$ By this assumption we follow, amongst others, Cheng et al. (2011). Note that the supply of a product variant with infinite quality is ruled out to be profitable by this profit function.
} 
The combination of equilibrium prices and qualities as depicted in Eq. (7) and Eq. (8) results in a unique equilibrium in which all $n$ variants are active and have a different quality. So, every product variant has a positive demand, price and quality. Note that the quality difference between sequential product variants, $q_{i-1}^{*}-q_{i}^{*}$, is constant and equals $2 \bar{\theta} / \alpha(1+2 n)$. This interval of quality-differentiated product variants is also reported by Mussa and Rosen (1978), and Cheng et al. (2011). Furthermore, it is easy to check that the highest quality variant, $i=1$, has a quality equal to $2 \bar{\theta} n / \alpha(1+2 n)$.

By substituting the equilibrium qualities, Eq. (8), into the expression for equilibrium prices, Eq. (7), we can check the price difference between sequential product variants. The price difference, $p_{i-1}^{*}-p_{i}^{*}=2 \bar{\theta}^{2}(2 n-i+2) /\left((1+2 n)^{2} \alpha^{2}\right)$, is, in contrast to the quality difference, not a constant. In fact, the price difference is increasing in $i$, so the price differential between neighbouring higher quality products is larger compared with neighbouring lower quality products. This has straightforward implications for the mark-up per product variant. Because the quality interval is constant, the marginal costs interval is also constant; however, the price interval is increasing. So, the mark-up needs to be higher for higher quality product variants, contradicting the constant mark-up property reported for the logit model by Anderson et al. (1992).

Intuitively, and as clearly shown in Eq. (7), the equilibrium prices are rising in the equilibrium qualities. Prices as well as qualities for all variants are increasing in the highest prevailing willingness to pay for quality, $\bar{\theta}$. In addition, prices are also decreasing in the generic price coefficient. Finally, an increase in the number of supplied product variants, $n$, has a positive effect on the quality of each product variant, and therefore on its price, which is consistent with the idea that the quality range is divided over more 
variants. ${ }^{11}$ Naturally, and in the absence of any fixed costs related to producing variants, the equilibrium profits are increasing in $n$. So, the monopolist obtains highest profits if $n$ goes to infinity. In that case, the profits are ${ }^{12}$ :

$$
\pi_{m \rightarrow \infty}=\frac{1}{12} \frac{\bar{\theta}^{2}}{\alpha^{2}}
$$

So, the profit of the monopolist is increasing in the highest implied willingness to pay for quality, $\bar{\theta}$, and decreasing in the generic price coefficient. We calculate welfare in order to analyse how vertical product differentiation in a monopoly affects welfare. Using surplus as a measure for welfare, it equals consumer surplus plus the profits of the monopolist, defined by: $W=C S+\pi_{m}$. The consumer surplus is the integral over the utility function for all types of consumers multiplied by the inverse of the marginal utility of income (Train, 2003, page 55): $C S=\frac{1}{\alpha} \int_{\underline{\theta}}^{\bar{\theta}} V(\theta, q) d \theta$. Due to the assumption of a uniform distribution of consumer's willingness to pay for quality, the consumer surplus can be conveniently calculated as:

$$
C S=\frac{1}{\alpha}\left(\left(y-\alpha p_{1}^{*}+\left(\frac{\bar{\theta}+\theta_{1}}{2}\right) q_{1}^{*}\right) x_{1}+\sum_{i=2}^{n}\left(y-\alpha p_{i}^{*}+\left(\frac{\theta_{i-1}+\theta_{i}}{2}\right) q_{i}^{*}\right) x_{i}+y x_{\text {out }}\right)
$$

The first complete term in the RHS of Eq. (10) deals exclusively with the highest quality product variant, whereas the second RHS term in Eq. (10) addresses all remaining $n-1$ product variants. Note that $\left(\theta_{i-1}+\theta_{i}\right) / 2$ is equal to the average $\theta$ over that range. So, the two complete terms within brackets

\footnotetext{
${ }^{11}$ So, for example, the highest quality product, $i=1$, has a higher quality for a larger $n$ as a result of being closer to perfect price discrimination.

${ }^{12}$ Calculations are available upon request. It is straightforward to show, as also stated by Mussa and Rosen (1978) and shown in Figure 2, that in this case the monopolist covers fifty per cent of the market.
} 
quantifies the average utility of all consumers buying a certain product variant $i$ with its equilibrium prices and qualities. By multiplying this average utility with the number of people buying this product variant, and adding over all variants, we arrive at the total consumer surplus. So, the total welfare function yields:

$$
W=\frac{1}{\alpha}\left(\left(y-\alpha p_{1}^{*}+\left(\frac{\bar{\theta}+\theta_{1}}{2}\right) q_{1}^{*}\right) x_{1}+\sum_{i=2}^{n}\left(y-\alpha p_{i}^{*}+\left(\frac{\theta_{i-1}+\theta_{i}}{2}\right) q_{i}^{*}\right) x_{i}+y x_{\text {out }}\right)+\sum_{i=1}^{n}\left(p_{i}-\frac{q_{i}^{2}}{2}\right) x_{i}
$$

Without loss of generality, we now normalise the utility from other goods, $y$, to zero, in order to simplify the consumer surplus calculations. Assuming that $n$ goes to infinity, we evaluate consumer surplus and profits to show that total welfare yields:

$$
W_{m}=C S+\pi_{m}=\frac{1}{8} \frac{\bar{\theta}^{2}}{\alpha^{2}}
$$

The fact that the monopolist supplies vertically differentiated products, is welfare increasing. In case the monopolist offers a single product variant, the profits equal $(2 / 27)\left(\bar{\theta}^{2} / \alpha^{2}\right)$, while the consumer surplus equals $(1 / 27)\left(\bar{\theta}^{2} / \alpha^{2}\right) \cdot{ }^{13}$ So, both profits and consumer surplus increase due to vertical product

${ }^{13}$ For $n=i=1$, the demand for this single variety, by applying Eq. (4) and Eq. (5), yields $x_{1}=\bar{\theta}-\left(\alpha p_{1} / q_{1}\right)$, furthermore the quality, Eq. (8), equals $(2 \bar{\theta}) /(3 \alpha)$, and by substituting the quality in Eq. (7) we derive the price: $(4 / 9)\left(\bar{\theta}^{2} / \alpha^{2}\right)$. Plugging the quality, price and demand in the profit function , Eq. (6), yields, after some rewriting, $\pi_{m}=(2 / 27)\left(\bar{\theta}^{2} / \alpha^{2}\right)$. Substituting the quality, price, and demand in Eq. (10), note that $\theta_{1}=\alpha p_{1} / q_{1}$, yields the consumer surplus: $(1 / 27)\left(\bar{\theta}^{2} / \alpha^{2}\right)$. 
differentiation under a monopoly. The difference in welfare between single- and multi-product monopolist is positively related to the highest prevailing willingness to pay for quality, $\bar{\theta}$.

Now, assume that a social planner sets prices and qualities in such a way that the welfare as depicted in Eq. (11) is optimised. Again, we evaluate consumer surplus, note that profits of the firm are equal to zero in the social optimum, assuming $n$ goes to infinity:

$$
W_{o}=\frac{1}{6} \frac{\bar{\theta}^{2}}{\alpha^{2}}
$$

The social optimum can be characterised by the same quality variants but lower prices for each variant compared with the monopoly outcome. Social surplus in the social optimum in Eq. (13), for equal $n$, always exceeds that for the monopoly outcome in Eq. (12). In fact, the social surplus in the monopoly is always, by dividing Eq. (12) by Eq. (13), 75 per cent of the welfare in the social optimum, treating $n$ as given.

The above findings are illustrated in Figure 2 below. The area between the solid line and the utility from other goods, $y$, represents the total welfare in the case the social planner sets the prices and qualities. In the social optimum, profits of the monopolist are zero and welfare coincides with the consumer surplus. The area between the long-dashed line and the utility from other goods, $y$, represent the welfare in the monopoly case. This is a summation of the profits and the consumer surplus, also shown in Figure $2 .^{14}$ The triangular area enclosed by $W_{o}, W_{m}$ and $y$, indicated by $A$, represents the welfare loss of the

\footnotetext{
${ }^{14}$ For example, an individual with a willingness to pay for quality of 0.5 chooses in the monopoly situation not to buy a product at all, receiving utility from all the other goods $y$, zero in this case, whereas in the social optimum she buys a product and has a corresponding utility of approximately 0.14 .
} 
monopoly in comparison with the social optimum in the absence of any fixed costs for supplying a product variant.

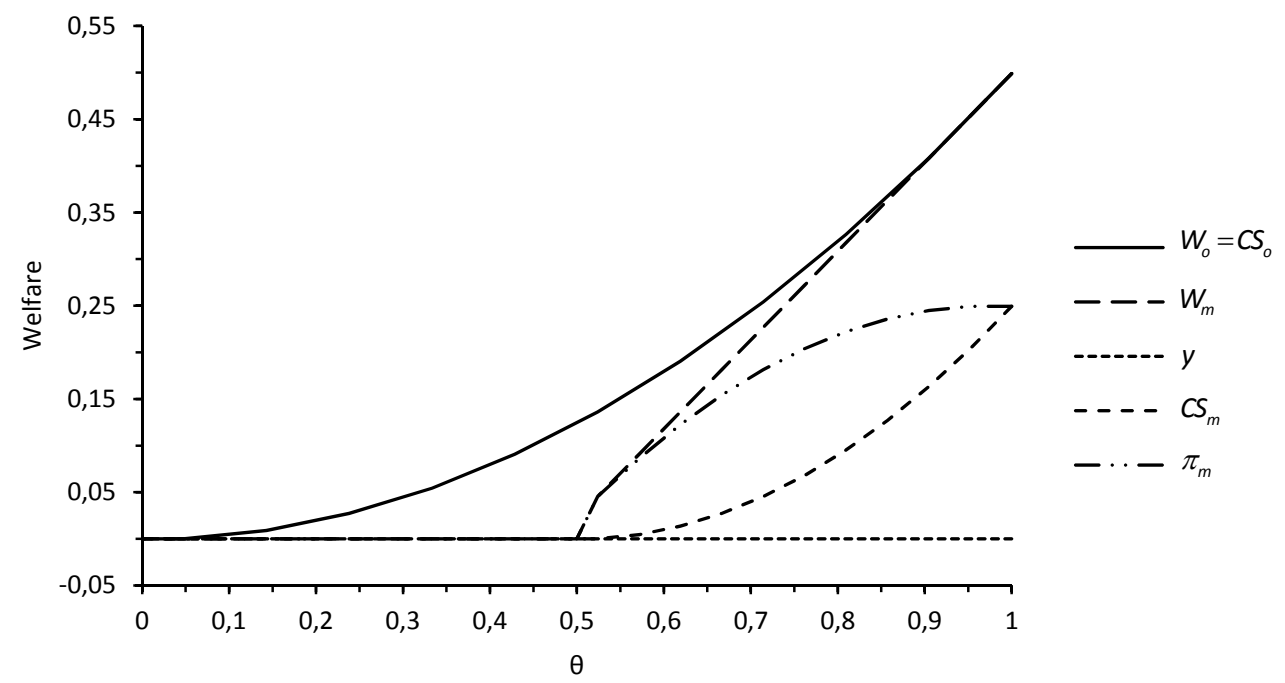

Figure 2 Welfare comparison between monopoly and social optimal outcome for $n \rightarrow \infty$.

\section{Multi-product monopoly facing random heterogeneous demand}

\subsection{Nested logit model}

Anderson et al. (1989 and 1992) study and use the random utility framework for numerous issues in product differentiation theory. Our model set-up can be looked at as a combination of the models studied by Anderson and de Palma (2001), Anderson and de Palma (1992b) and Anderson and de Palma (1992a) on the logit model and quality choice, the multi-product oligopoly, and product selection and price competition. 
We specify a nested logit model, because the structure of this model enables us to capture the differences in unobserved product heterogeneity between the products of the monopolist at one hand, and the unobserved heterogeneity between the products of the monopolist and the outside alternative, not buying at all, at the other. ${ }^{15}$ Using this model, we are able to compare the profit maximising patterns of product differentiation between the deterministic and random-utility demand model.

Our two-level nested logit model is depicted in Figure 3. The different product variants are the elemental alternatives nested by firm, which is in our case only the monopolist. The outside alternative, $y$, is the single, degenerated, elemental alternative in a separate nest. Therefore, the two nests may be interpreted as buying, or not buying at all instead. The nested structure does not indicate a behavioural decision sequence of the consumers. Instead it indicates that the product variants within a nest (a firm) are more similar compared with product variants in other nests (other firms, outside alternative) in unobserved attributes as perceived by the consumers.

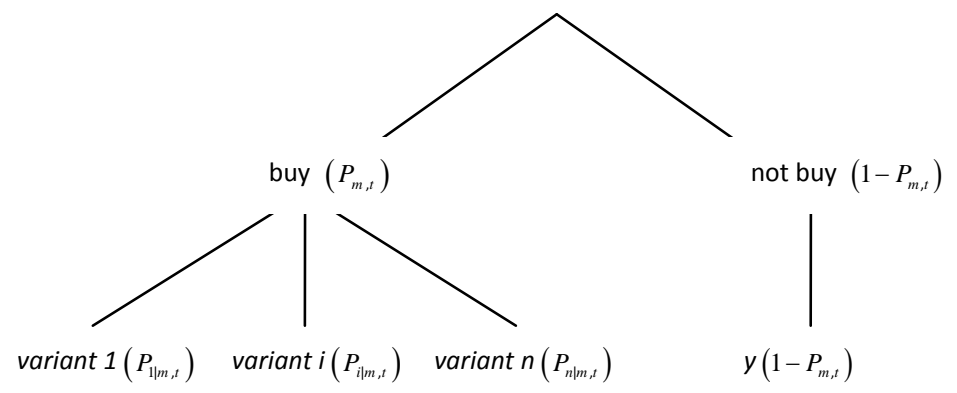

Figure 3 Nested demand structure for a multi-product monopolist.

\footnotetext{
${ }^{15}$ Note that by specifying a nested logit model, we need to disentangle the error term included in Eq. (3) in two parts. A first part, say $\varepsilon_{\gamma t}$ only captures the unobserved components varying over the product variants (lower level in Figure 3 ), and a second part, say $\varepsilon_{\rho t}$, only captures the unobserved components varying over the nests buying versus non-buying (upper level in Figure 3).
} 
Using standard nested logit expressions, we define the demand for each product variant $i$ of monopolist $m$ as follows:

$$
x_{i}=\sum_{t=1} \mathrm{P}_{i m, t}, \quad i=1, \ldots, n,
$$

with $\mathrm{P}_{i m, t}=\mathrm{P}_{i \mid m, t} \mathrm{P}_{m, t}$. So, each consumer type $t$ has a demand equal to the conditional probability of choosing product variant $i$ given that they buy the product, multiplied by the probability that they actually buy the product. The total demand for product variant $i$ is the summation over all consumer types $t, t \in T$. Each consumer type differs in their willingness to pay for quality $\theta / \alpha .{ }^{16}$ Furthermore, we assume that consumers are uniformly distributed over the different $T$ type. The conditional probability is defined as:

$$
\mathrm{P}_{i \mid m, t}=\frac{\exp \left(\frac{y-\alpha p_{i}+\theta_{t} q_{i}}{\mu_{2}}\right)}{\sum_{i=1}^{n} \exp \left(\frac{y-\alpha p_{i}+\theta_{t} q_{i}}{\mu_{2}}\right)},
$$

and the probability of actually buying a product from monopolist $m$ as:

$$
\mathrm{P}_{m, t}=\frac{\exp \left(S_{m, t} / \mu_{1}\right)}{\exp \left(S_{m, t} / \mu_{1}\right)+\exp \left(y / \mu_{1}\right)},
$$

\footnotetext{
${ }^{16}$ Like in latent class modelling, our model over $T$ types of consumers uses a discrete number of evaluating points $T$ to describe the joint distribution of price and quality parameters of the model. One could also specify a continuous distribution to describe this joint distribution and arrive at a more flexible mixed logit model instead. Nevertheless, we prefer the nested logit models because it has, in contrast with the mixed logit, a closed-form solution and the structure of the model in terms of unobserved heterogeneity fits the market structure at hand.
} 
with the so-called logsum, $S_{m, t}$, defined as:

$$
S_{m, t}=\mu_{2} \ln \left(\sum_{i=1}^{n} \exp \left(\frac{y-\alpha p_{i}+\theta_{t} q_{i}}{\mu_{2}}\right)\right) \text {. }
$$

The two so-called scale parameters, $\mu_{1}$ and $\mu_{2}$, determine the variance of the unobserved components in the utility function. The variance in unobserved components associated with the elemental alternative, the lower level of Figure 3, is represented by $\mu_{2}$, whereas $\mu_{1}$ represent this variance associated with the the nest, the upper level in Figure 3. The model as described in Eq. (14) to Eq. (17) offers a direct expression for consumer surplus. The consumer surplus is the summation of the expected indirect utility for each consumer type $t$ (Ben-Akiva and Lerman, 1985):

$$
C S=\frac{1}{\alpha} \sum_{t=1} \mu_{1} \ln \left(\frac{\mu_{2} \ln \left(\sum_{i=1}^{n} \exp \left(\frac{y-\alpha p_{i}+\theta_{t} q_{i}}{\mu_{2}}\right)\right)+\exp (y)}{\mu_{1}}\right)
$$

To compare consumer surplus as depicted in Eq. (18) with the deterministic form as shown in Eq.(10), we need to normalise Eq. (18) by dividing the CS by $T$.

The monopolist aims to maximise profits and behaves accordingly. We use the same profit function for the monopolist as in the deterministic case, Eq. (6), however the demand, $x_{i}$, is now specified as in Eq. (14). We solve the model taking the first order conditions of the profit function with respect to prices and qualities. 
Unfortunately, due to the non-linear nature of the nested logit model, and in fact any logit model, the model does not have any interpretable explicit analytical solutions in prices and/or qualities. In addition, due to the aggregation over $T$ consumer types, the implicit analytical solutions do not offer any useful insights. In Appendix A, we state these implicit first-order conditions and show that if we assume one consumer type $t^{*}$, the implicit solution for the profit maximising prices equals the one given by Anderson et al. (1992, page 251). Given the complexity of the implicit solutions, we focus on numerical solutions in the remainder of this Section. ${ }^{17}$

\subsection{Unobserved inter- and intra-product heterogeneity}

The scale parameters, $\mu_{1}$ and $\mu_{2}$, set the variance of the unobserved components of the utility. These unobserved components are also referred to in the literature as unobserved inter- and intra-product (firm) heterogeneity (Anderson et al., 1992, page 250) and are represented by error terms, say $\varepsilon_{\gamma t}$ for the elemental alternatives, and $\varepsilon_{\rho t}$ for the nests.

Both error terms follow a double exponential distribution with a mean equal to zero and a variance equal to $\mu_{2}^{2}\left(\pi^{2} / 6\right)$ and $\mu_{1}^{2}\left(\pi^{2} / 6\right)$ respectively. The variance increases in the scale parameters. A higher value of the variance, whether through an increase in $\mu_{1}, \mu_{2}$ or both, means that the systematic part of the utility, $y-\alpha p_{i}+\theta_{t} q_{i}$, becomes a less important factor in determining whether and which variant a consumer buys. Or, stated alternatively, an increase in the variance via $\mu_{2}$ makes the demand for a particular variant less sensitive to its own price-quality setting, whereas an increase in the variance

\footnotetext{
${ }^{17}$ For all numerical optimisation results, we calculated the accompanying Hessian matrix and evaluated the appropriate determinants of this matrix in order to guarantee the existence of the equilibrium. The uniqueness properties of the logit model are discussed extensively by Anderson et al. (1992).
} 
via $\mu_{1}$ makes the demand for whether or not buying a product at all less sensitive to the maximum expected utility, the logsum, of buying the product.

In the special case that the variance of both error terms approaches zero, and therefore both scale parameters approach zero, the nested logit model reduces to the deterministic model as discussed in the previous section.

Consistency with random utility theory requires the unobserved heterogeneity at the upper level of the nested logit, see Figure 3, to be larger compared with the unobserved heterogeneity at the lower level of the nested logit. In our case this means that $\mu_{1}>\mu_{2}$, which has the straightforward interpretation that product variants are more similar in unobserved characteristics amongst each other, compared with the not-buying-at-all alternative. A final restriction on the parameterisation of the scale parameters is dictated by the inclusion of the outside, degenerated alternative. Having one elemental alternative in the nest requires the scale parameters at both levels need to be equal. ${ }^{18}$

In the Figures 4, 5, and 6 we show how the expected market shares (probabilities) for each product variant varies over the range of willingness to pay for quality for three different "extreme" sets of values of the scale parameters. In contrast to Figure 1, the expected market shares in the figures below are now based on the actual profit maximising price and quality for each product variant. Assuming three product variants, and $\alpha=1$ and $\bar{\theta}=2$ for the three figures, we first discuss the case in which both scale parameters are virtually zero.

\footnotetext{
${ }^{18}$ In estimating nested logit models, only the ratio of the two scale parameters can be identified. This requires normalisation of the scale of one of the two levels, normally the upper level, at, for example, 1.
} 
Due to the parameterisation of the scale parameters, the expected market shares in Figure 4 sharply react to the level of the systematic utility which varies per product variant for each consumer type. For example, the probability of choosing product variant $1, \mathrm{P}_{1 m, t}$, directly approaches 1 at the moment the marginal consumer $\theta_{1}$, here around 1.72, prefers product variant 1 over 2 in observed utility components. On the secondary $y$-axis the observed utility per product variant for each consumer type is depicted reflecting the deterministic model. Due to the absence of any variation in the random components the nested logit model equals the deterministic model.

Figure 5 illustrates the case in which the scale parameter associated with the elemental alternative is virtually zero and the one associated with the nest is normalised to one. The expected market shares are still fully responsive to the differences in the systematic utility, but now only for the choice between the product variants and no longer for the choice between buying or not buying at all. If we further increase the value of the scale parameter of the elemental alternative to 0.5 , we arrive at Figure 6 . In that case, the expected market shares are hardly responsive anymore to the differences in systematic utility between the product variants on the one hand, and buying versus not buying at all on the other. We conclude that the parameterisation of the nested logit model, or the empirical validation of its scale parameters, largely influences the ability of the nested logit model to analyse vertical product differentiation from a theoretical perspective. In fact, as will become clear in the next section, the random utility framework is only useful if the relative importance of the observed utility compared with the unobserved utility is substantive. 


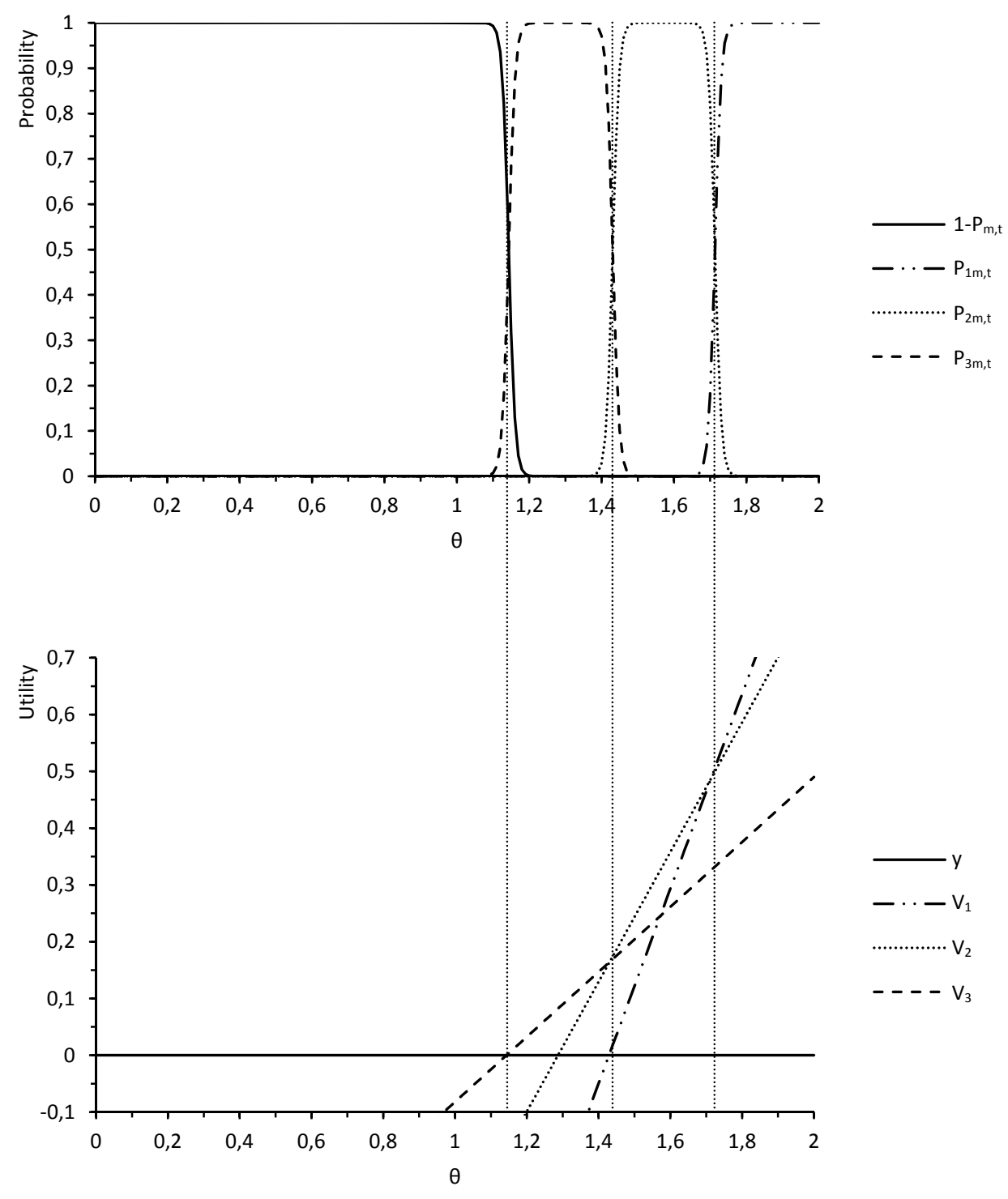

Figure 4 Market share over $\theta$ for random (upper panel) and deterministic (lower) utility for three product variants, with $\alpha=1, \bar{\theta}=2, \mu_{1}=0.001$, and $\mu_{2}=0.001$. 


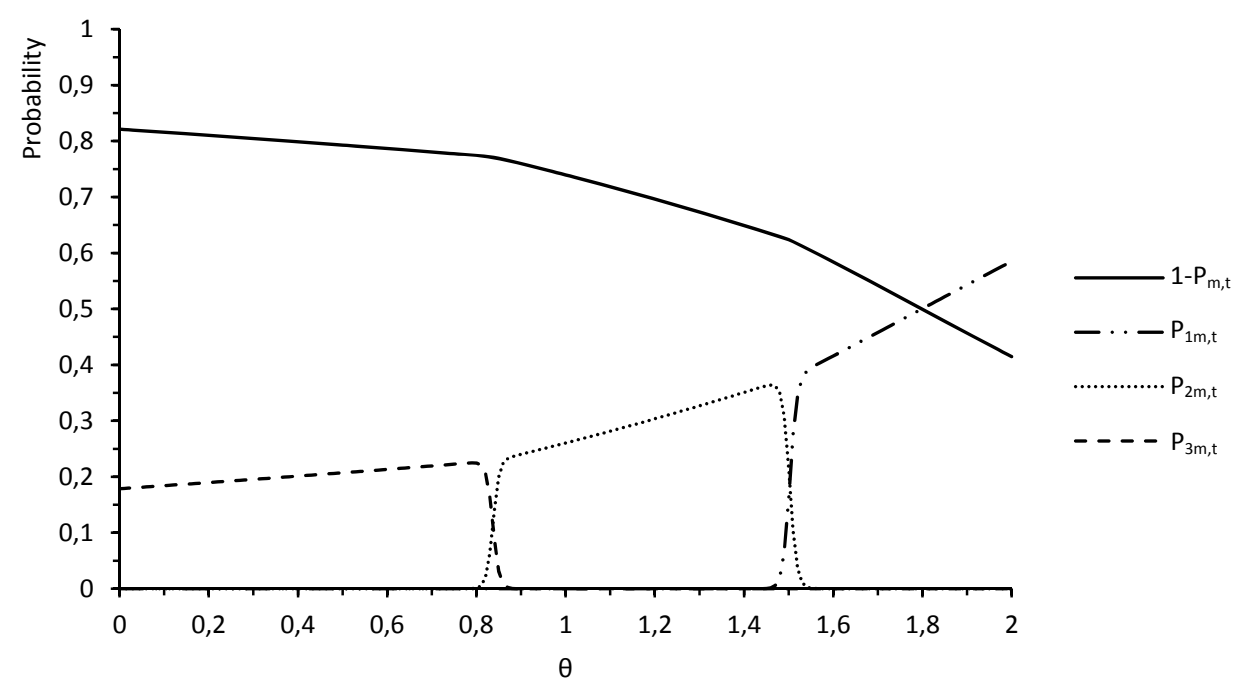

Figure 5 Market share over $\boldsymbol{\theta}$ for random (primary vertical axis) and deterministic (secondary vertical axis) utility for three product variants, with $\alpha=1, \bar{\theta}=2, \mu_{1}=1$, and $\mu_{2}=0.001$.

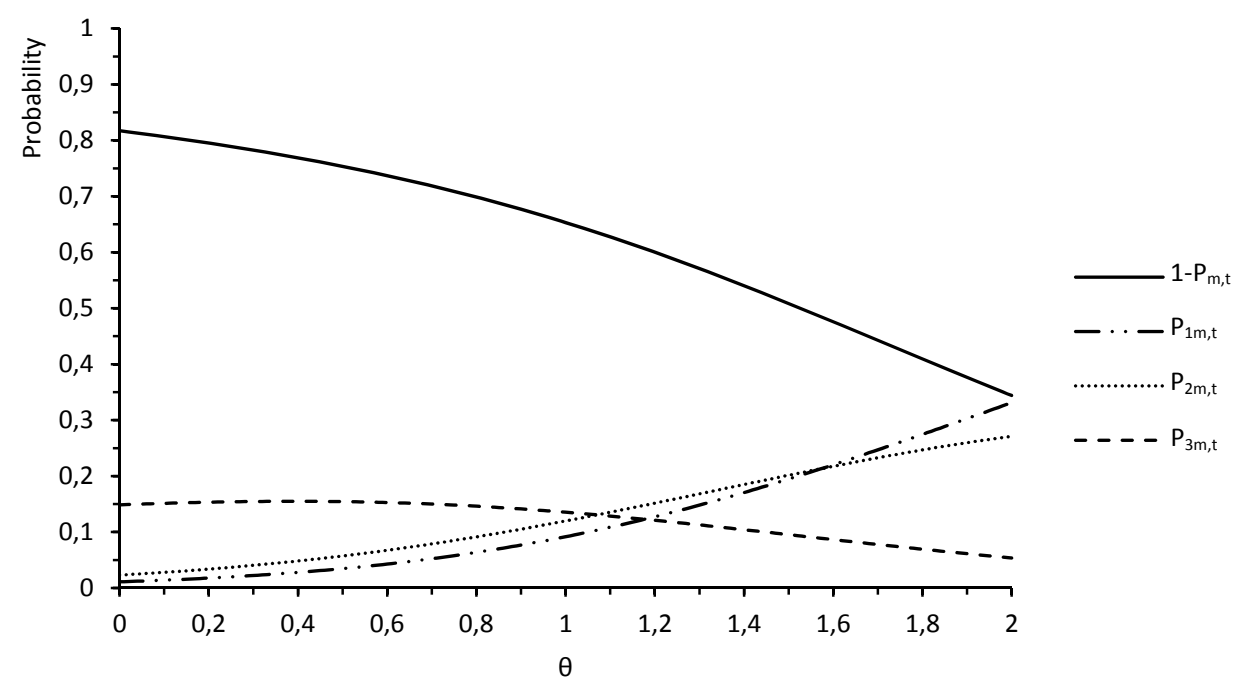

Figure 6 Market share over $\theta$ for random (primary vertical axis) and deterministic (secondary vertical axis) utility for three product variants, with $\alpha=1, \bar{\theta}=2, \mu_{1}=1$, and $\mu_{2}=0.5$. 


\subsection{Numerical results}

The full numerical results for product differentiation patterns in case of deterministic and random utility models are shown in Table 1 and Table 2. The patterns of product differentiation are a result of the profit maximising behaviour of the monopolist facing different parameter values for $\bar{\theta}$ and $\mu_{2}$.

Irrespective of the different parameter values or utility models, the monopolist maximises its profits by supplying an infinite number of product variants. However, for reasons of tractability, we limit the numerical results to supplying two product variants in Table 1 and five variants in Table 2 . We evaluate the numerical results assuming $\alpha=1, \mu_{1}=1$ and $\underline{\theta}=0$ and postpone the discussion about the welfare implications, as shown in the last five lines of both tables, to the next Section.

\begin{tabular}{|c|c|c|c|c|c|c|c|c|c|c|c|c|}
\hline & \multicolumn{3}{|c|}{ Deterministic } & \multicolumn{9}{|c|}{ Random Utility } \\
\hline & \multirow[b]{2}{*}{$\bar{\theta}=1$} & \multirow[b]{2}{*}{$\bar{\theta}=2$} & \multirow[b]{2}{*}{$\bar{\theta}=5$} & \multicolumn{3}{|c|}{$\mu_{2}=0.1$} & \multicolumn{3}{|c|}{$\mu_{2}=0.5$} & \multicolumn{3}{|c|}{$\mu_{2}=0.9$} \\
\hline & & & & $\bar{\theta}=1$ & $\bar{\theta}=2$ & $\bar{\theta}=5$ & $\bar{\theta}=1$ & $\bar{\theta}=2$ & $\bar{\theta}=5$ & $\bar{\theta}=1$ & $\bar{\theta}=2$ & $\bar{\theta}=5$ \\
\hline$p_{1}$ & 0.56 & 2.24 & 14.00 & 1.47 & 2.81 & 13.44 & 1.54 & 2.25 & 13.30 & 1.62 & 2.32 & 12.89 \\
\hline$p_{2}$ & 0.24 & 0.96 & 6.00 & 1.47 & 1.65 & 4.93 & 1.54 & 2.25 & 5.11 & 1.62 & 2.32 & 7.98 \\
\hline$q_{1}$ & 0.80 & 1.60 & 4.00 & 0.52 & 1.56 & 3.87 & 0.52 & 1.12 & 3.84 & 0.52 & 1.09 & 3.70 \\
\hline$q_{2}$ & 0.40 & 0.80 & 2.00 & 0.52 & 0.59 & 1.62 & 0.52 & 1.12 & 1.66 & 0.52 & 1.09 & 2.45 \\
\hline mark-up 1 & 0.24 & 0.96 & 6.00 & 1.33 & 1.60 & 5.95 & 1.40 & 1.62 & 5.94 & 1.49 & 1.72 & 6.03 \\
\hline mark-up 2 & 0.16 & 0.64 & 4.00 & 1.33 & 1.47 & 3.62 & 1.40 & 1.62 & 3.75 & 1.49 & 1.72 & 4.97 \\
\hline market share $_{1}$ & 0.20 & 0.20 & 0.20 & 0.12 & 0.17 & 0.23 & 0.14 & 0.16 & 0.23 & 0.16 & 0.18 & 0.19 \\
\hline market share $_{2}$ & 0.20 & 0.20 & 0.20 & 0.12 & 0.13 & 0.18 & 0.14 & 0.16 & 0.18 & 0.16 & 0.18 & 0.18 \\
\hline market share $_{m}$ & 0.40 & 0.40 & 0.40 & 0.24 & 0.30 & 0.41 & 0.28 & 0.33 & 0.41 & 0.32 & 0.36 & 0.38 \\
\hline profit $_{m}$ & 0.08 & 0.32 & 2.00 & 0.32 & 0.47 & 2.02 & 0.40 & 0.53 & 2.03 & 0.48 & 0.63 & 2.07 \\
\hline$C S_{m}$ & 0.04 & 0.16 & 1.00 & 0.28 & 0.38 & 1.15 & 0.34 & 0.42 & 1.16 & 0.39 & 0.48 & 1.16 \\
\hline$C S_{o}$ & 0.16 & 0.64 & 4.00 & 0.80 & 1.10 & 4.18 & 0.96 & 1.24 & 4.19 & 1.14 & 1.44 & 4.30 \\
\hline$W_{m}$ & 0.12 & 0.48 & 3.00 & 0.61 & 0.85 & 3.18 & 0.73 & 0.96 & 3.20 & 0.88 & 1.11 & 3.24 \\
\hline$w_{o}$ & 0.16 & 0.64 & 4.00 & 0.80 & 1.10 & 4.18 & 0.96 & 1.24 & 4.19 & 1.14 & 1.44 & 4.30 \\
\hline$W_{m} / W_{o}$ & 0.75 & 0.75 & 0.75 & 0.75 & 0.77 & 0.76 & 0.76 & 0.77 & 0.76 & 0.77 & 0.77 & 0.75 \\
\hline
\end{tabular}

Table 1 Random utility model and deterministic model equilibriums, $n=2, \mu_{1}=1, \alpha=1$. 


\begin{tabular}{|c|c|c|c|c|c|c|c|c|c|c|c|c|}
\hline & \multicolumn{3}{|c|}{ Deterministic } & \multicolumn{9}{|c|}{ Random Utility } \\
\hline & \multirow[b]{2}{*}{$\bar{\theta}=1$} & \multirow[b]{2}{*}{$\bar{\theta}=2$} & \multirow[b]{2}{*}{$\bar{\theta}=5$} & \multicolumn{3}{|c|}{$\mu_{2}=0.1$} & \multicolumn{3}{|c|}{$\mu_{2}=0.5$} & \multicolumn{3}{|c|}{$\mu_{2}=0.9$} \\
\hline & & & & $\bar{\theta}=1$ & $\bar{\theta}=2$ & $\bar{\theta}=5$ & $\bar{\theta}=1$ & $\bar{\theta}=2$ & $\bar{\theta}=5$ & $\bar{\theta}=1$ & $\bar{\theta}=2$ & $\bar{\theta}=5$ \\
\hline$p_{1}$ & 0.66 & 2.64 & 16.53 & 1.49 & 2.78 & 16.32 & 1.68 & 2.37 & 14.14 & 1.93 & 2.58 & 12.37 \\
\hline$p_{2}$ & 0.50 & 1.98 & 12.40 & 1.49 & 2.78 & 11.99 & 1.68 & 2.37 & 14.14 & 1.93 & 2.58 & 12.37 \\
\hline$p_{3}$ & 0.35 & 1.39 & 8.68 & 1.49 & 2.78 & 8.34 & 1.68 & 2.37 & 9.27 & 1.93 & 2.58 & 12.37 \\
\hline$p_{4}$ & 0.21 & 0.86 & 5.37 & 1.49 & 1.64 & 5.11 & 1.68 & 2.37 & 6.16 & 1.93 & 2.58 & 3.79 \\
\hline$p_{5}$ & 0.10 & 0.40 & 2.48 & 1.49 & 1.64 & 2.32 & 1.68 & 2.37 & 2.81 & 1.93 & 2.58 & 3.79 \\
\hline$q_{1}$ & 0.91 & 1.82 & 4.45 & 0.52 & 1.52 & 4.49 & 0.51 & 1.08 & 3.97 & 0.50 & 1.02 & 3.50 \\
\hline$q_{2}$ & 0.73 & 1.45 & 3.64 & 0.52 & 1.52 & 3.52 & 0.51 & 1.08 & 3.97 & 0.50 & 1.02 & 3.50 \\
\hline$q_{3}$ & 0.55 & 1.09 & 2.73 & 0.52 & 1.52 & 2.61 & 0.51 & 1.08 & 2.79 & 0.50 & 1.02 & 3.50 \\
\hline$q_{4}$ & 0.36 & 0.73 & 1.82 & 0.52 & 0.54 & 1.64 & 0.51 & 1.08 & 1.92 & 0.50 & 1.02 & 1.04 \\
\hline$q_{5}$ & 0.18 & 0.36 & 0.91 & 0.52 & 0.54 & 0.47 & 0.51 & 1.08 & 0.70 & 0.50 & 1.02 & 1.04 \\
\hline mark-up $_{1}$ & 0.25 & 0.99 & 6.20 & 1.35 & 1.63 & 6.25 & 1.55 & 1.79 & 6.26 & 1.80 & 2.06 & 6.26 \\
\hline mark-up 2 & 0.23 & 0.93 & 5.79 & 1.35 & 1.63 & 5.79 & 1.55 & 1.79 & 6.26 & 1.80 & 2.06 & 6.26 \\
\hline mark-up $_{3}$ & 0.20 & 0.79 & 4.96 & 1.35 & 1.63 & 4.95 & 1.55 & 1.79 & 5.38 & 1.80 & 2.06 & 6.26 \\
\hline mark-up $_{4}$ & 0.15 & 0.60 & 3.72 & 1.35 & 1.50 & 3.76 & 1.55 & 1.79 & 4.32 & 1.80 & 2.06 & 3.25 \\
\hline mark-up 5 & 0.08 & 0.33 & 2.07 & 1.35 & 1.50 & 2.21 & 1.55 & 1.79 & 2.56 & 1.80 & 2.06 & 3.25 \\
\hline market share $_{1}$ & 0.09 & 0.09 & 0.09 & 0.05 & 0.06 & 0.10 & 0.07 & 0.08 & 0.09 & 0.09 & 0.10 & 0.10 \\
\hline market share 2 & 0.09 & 0.09 & 0.09 & 0.05 & 0.06 & 0.10 & 0.07 & 0.08 & 0.09 & 0.09 & 0.10 & 0.10 \\
\hline market share $_{3}$ & 0.09 & 0.09 & 0.09 & 0.05 & 0.06 & 0.09 & 0.07 & 0.08 & 0.09 & 0.09 & 0.10 & 0.10 \\
\hline market share $_{4}$ & 0.09 & 0.09 & 0.09 & 0.05 & 0.06 & 0.08 & 0.07 & 0.08 & 0.09 & 0.09 & 0.10 & 0.09 \\
\hline market share $_{5}$ & 0.09 & 0.09 & 0.09 & 0.05 & 0.06 & 0.07 & 0.07 & 0.08 & 0.09 & 0.09 & 0.10 & 0.09 \\
\hline market share $_{\mathrm{m}}$ & 0.45 & 0.45 & 0.45 & 0.26 & 0.31 & 0.45 & 0.35 & 0.39 & 0.45 & 0.44 & 0.49 & 0.48 \\
\hline profit $_{m}$ & 0.08 & 0.33 & 2.06 & 0.35 & 0.49 & 2.12 & 0.54 & 0.70 & 2.24 & 0.80 & 0.98 & 2.43 \\
\hline $\mathrm{CS}_{\mathrm{m}}$ & 0.04 & 0.16 & 1.03 & 0.30 & 0.40 & 1.20 & 0.43 & 0.53 & 1.27 & 0.59 & 0.68 & 1.38 \\
\hline $\mathrm{CS}_{\mathrm{o}}$ & 0.16 & 0.66 & 4.13 & 0.85 & 1.16 & 4.35 & 1.27 & 1.58 & 4.60 & 1.77 & 2.11 & 4.99 \\
\hline$W_{m}$ & 0.12 & 0.50 & 3.10 & 0.65 & 0.89 & 3.33 & 0.98 & 1.23 & 3.51 & 1.39 & 1.66 & 3.81 \\
\hline$w_{o}$ & 0.16 & 0.66 & 4.13 & 0.85 & 1.16 & 4.35 & 1.27 & 1.58 & 4.60 & 1.77 & 2.11 & 4.99 \\
\hline $\mathrm{W}_{\mathrm{m}} / \mathrm{W}_{\mathrm{o}}$ & 0.75 & 0.75 & 0.75 & 0.76 & 0.77 & 0.77 & 0.77 & 0.78 & 0.76 & 0.78 & 0.78 & 0.76 \\
\hline
\end{tabular}

Table 2 Random utility model and deterministic model equilibriums, $n=5, \mu_{1}=1, \alpha=1$.

As expected, the equilibrium prices, qualities, mark-ups and profits increase, ceteris paribus, in $\bar{\theta}$. In the deterministic model, the market shares do not depend on $\bar{\theta}$ because the monopolist offers fixed quality intervals, as shown in Eq. (8), and adjusts the prices and qualities accordingly. In the random utility model an increase in $\bar{\theta}$ has an effect on the market shares of each product variant because a higher $\bar{\theta}$ implies a larger probability that people actually buy higher quality variants and the product at all. 
Furthermore, the mark-up and market share of the highest quality variant is the largest for both models and all parameter values. ${ }^{19}$ The effect of unobserved inter-product heterogeneity, $\mu_{2}$, on equilibrium prices, qualities, mark-ups, market shares, and profit is positive. So, if the consumer becomes less sensitive regarding the observed part of the utility function, for example consumers have strong but not observable preferences for certain product variants, the monopoly can increase its mark-up freely, by setting higher prices for the same quality, without affecting the expected demand (market shares) for the variant.

We define an equilibrium to be symmetric if and only if prices and qualities of all product variants supplied by a single firm are equal. In contrast, the asymmetric equilibrium can have overlapping, i.e. subsets of symmetric product variants, as long as at least two product variants supplied by a single firm differ in prices and qualities. In case prices and qualities of all product variants supplied by a singly firm vary, we define this as a fully differentiated equilibrium, so $p_{1}>p_{2}>p_{n}$ and $q_{1}>q_{2}>q_{n}$.

As expected based on Eq. (7) and Eq. (8), fully differentiated equilibriums are found for all parameter values in the deterministic model. However, in the random utility model we observe for the combination of low values of $\bar{\theta}$ and high values of $\mu_{2}$ symmetric equilibriums. For example, with $\mu_{2}=0.9$ the equilibrium is symmetric for 2 product variants in case $\bar{\theta}$ equals 1 or 2 , whereas for 5 product variants not even a partially differentiated equilibrium exists for $\bar{\theta}=1$ and $\bar{\theta}=2$.

\footnotetext{
${ }^{19}$ One would expect in reality that mark-ups are positively ranked by quality, but that this does not hold for market shares. The exclusive, top quality product variant, would normally not have the highest market share. The reason behind these results is the assumed uniform distribution of willingness to pay, whereas in reality we would expect that the potential market base for the top quality variants is more limited.
} 
Because $\bar{\theta}$, in combination with a constant $\underline{\theta}$, indicates the dispersion of willingness to pay for quality, this dispersion affects the pattern of product differentiation. Intuitively, the monopolist differentiates more if the dispersion of the observed willingness to pay increases. The effect of $\mu_{2}$ on the pattern of product differentiation is in line with the aforementioned observation that the importance of the systematic part of the utility, so the realised prices, qualities and associated sensitivities, diminishes in determining whether and which product variant the consumer buys if $\mu_{2}$ increases. Hence, an increase in $\mu_{2}$ partly offsets the observed dispersion of willingness to pay for quality amongst consumers or makes this dispersion less important in the behaviour of the consumers.

Figure 7 shows the contour line as a function of $\bar{\theta}$ and $\mu_{2}$. Below this line, a fully differentiated equilibrium exists and above the line the equilibrium is symmetric, or asymmetric with overlapping product variants with at least two product variants differing in prices and qualities. The contour line is drawn for two, three, four and five product variants respectively, and with $\bar{\theta}=7$ and $\mu_{2}=1$ as upper limits. In essence, the figure shows under which conditions of the key parameters of the nested logit model realistic patterns of fully differentiated equilibriums occur. In general, the nested logit model predicts fully differentiated patterns of product differentiation if the unobserved product heterogeneity, $\mu_{2}$, relative to the observed dispersion of willingness to pay for quality, $\bar{\theta}-\underline{\theta}$, is small. Naturally, the more product variants are supplied, the more restrictive the parameters values for fully differentiated equilibriums become.

These findings show that the random utility framework can be applied to study vertical product differentiation without the drawback of only analysing non-realistic symmetric patterns of product differentiation and without assuming deterministic demand. The requirement that the dispersion of willingness to pay for quality in the random utility model should be large enough, looks familiar to the 
requirement of $\bar{\theta}>2 \underline{\theta}$ in the duopolistic deterministic model (see e.g. Tirole (1988)), although a strict magnitude for $\bar{\theta}-\underline{\theta}$ cannot be indicated.

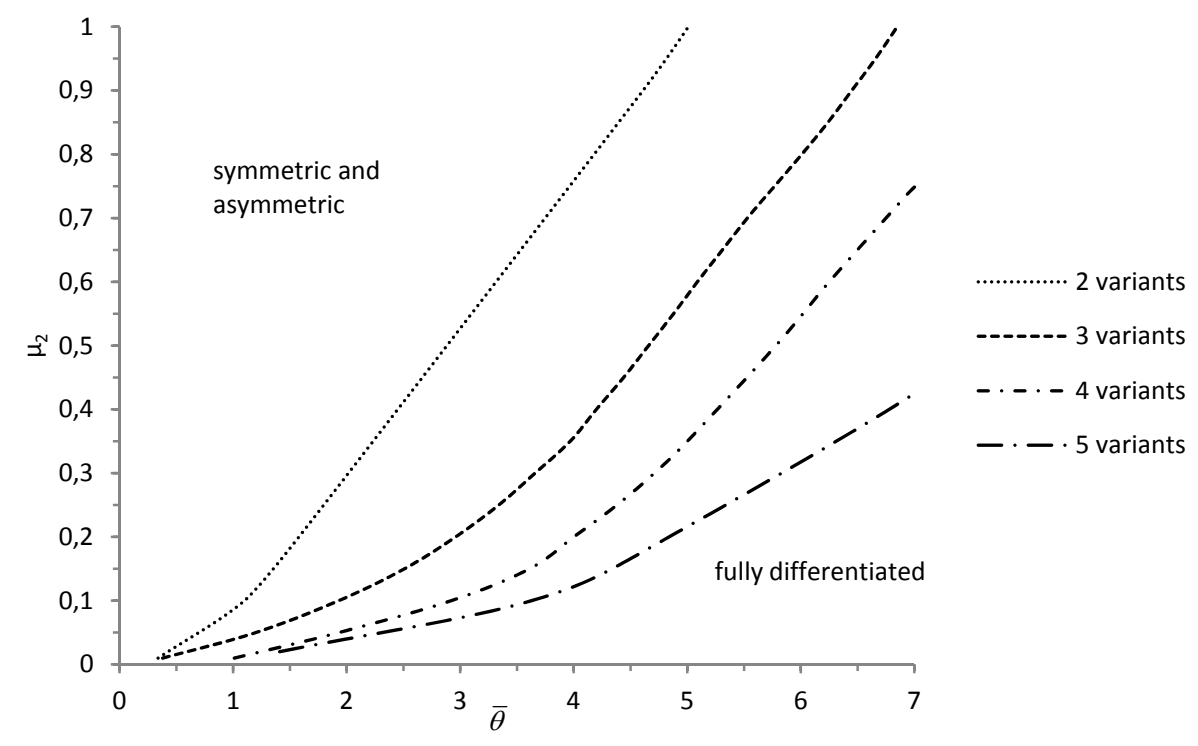

Figure 7 Symmetric versus asymmetric equilibriums.

\subsection{Welfare comparison}

We compare the welfare in two regimes. In the first regime, the monopolist maximises its profits whereas in the second one a social planner maximises welfare. The welfare function is the sum of our measure of consumer surplus, the so-called logsum, and monopoly profits:

$$
W=\frac{1}{\alpha} \sum_{t=1} \mu_{1} \ln \left(\frac{\mu_{2} \ln \left(\sum_{i=1}^{n} \exp \left(\frac{y-\alpha p_{i}+\theta_{t} q_{i}}{\mu_{2}}\right)\right)+\exp (y)}{\mu_{1}}\right)+\sum_{i=1}^{n}\left(p_{i}-\frac{q_{i}^{2}}{2}\right) x_{i} .
$$


The last five lines of Table 1 and Table 2 summarise the welfare measures of the two regimes, whereas in Table 3 and Table 4 in Appendix B full results of the welfare optimising equilibriums are shown. As can be readily verified by comparing the full results of Table 1 with Table 3, and Table 2 with Table 4 respectively, in both regimes the same product variants, in terms of quality, are supplied but for a higher price. The multi-product monopolist supplies the social optimal quality but adds a mark-up, resulting in higher than social optimal prices for all product variants. This result holds for both the deterministic and random utility model, and for all parameter values irrespective whether the equilibrium is symmetric or asymmetric. $^{20}$ So, the differences in welfare are a result of the difference in price setting only. Due to this overpricing, consumers with a larger willingness to pay for the product compared with the social costs of supplying this product may choose not to buy the product, resulting in a welfare loss. The market share of buying the product in case of welfare maximising is roughly twice the market share in case the monopolist optimises profits. ${ }^{21}$

We conclude, based on the last five lines in Table 1 and Table 2, that the welfare efficiency, which equals 0.75 times the welfare obtained in the social optimum, is independent on both observed and unobserved demand heterogeneity. ${ }^{22}$ The reason that the observed dispersion in willingness to pay for quality does not alter relative efficiency is that the monopolist supplies the social optimal qualities given the heterogeneity across consumers. The way the monopolist sets its prices is not affected by the level of observed heterogeneity, only the outcome is adjusted accordingly to the new optimal qualities. For the social planner, a change in observed heterogeneity across consumer also results into other optimal

\footnotetext{
${ }^{20}$ The social optimal price equals the marginal costs of supplying the particular product variant: $q_{i}^{2} / 2$.

${ }^{21}$ Note that with welfare maximisation and the number of product variants going to infinity, all consumers with a positive willingness to pay for quality buy a product variant, whereas the pricing strategy of the profit maximising monopolist results in only half of the consumers, the fifty per cent with the highest willingness to pay for quality, buying a product.

${ }^{22}$ In contrast, the absolute welfare loss depends on $\bar{\theta}$, subtract Eq. (12) from Eq. (13) to get: $(1 / 24)\left(\bar{\theta}^{3} / \alpha\right)$. Note that the latter expression is only valid in the special case that the demand is totally deterministic.
} 
qualities, and accordingly adjusted prices. However, the rules for determining optimal or profit maximising pricing do not alter by a change in observed heterogeneity. Therefore, such a change would equally affect the monopolist and the social planner, resulting in a comparison between the two regimes in which a constant welfare efficiency is expected and observable.

The same reasoning holds regarding unobserved heterogeneity. The scale parameters have the same effect on the profit function to be maximised by the monopoly, and the welfare function to be maximised by the social planner. Therefore, the relative efficiency of the two welfare outcomes do not depend on the this scale parameter. As a consequence, the relative welfare efficiency between the deterministic model and the random utility model is constant as well.

\section{Conclusion}

Product differentiation, whether horizontal, vertical or a combination of both, is an important characteristic of many industries. Not only do different firms supply different variants of a product, also a single firm may supply different variants. As far as we are aware, in this article we are the first to show that the patterns of vertical product differentiation for a multi-product monopoly can be explained using random utility models.

We confirm that the commonly used deterministic utility model is a special case of the more general random utility framework with respect to predicted equilibrium patterns of vertical product differentiation. The use of the random utility framework offers two advantages over the deterministic approach. First, we relax the assumption that consumer preferences are completely observable, by accounting for unobserved heterogeneity. Second, the random utility model is often used in empirical 
work to study consumer behaviour in markets characterised by multi-product firms and vertical product differentiation. Our article shows that, from a theoretical point of view, the random utility framework can also be used. One may therefore see theoretical and empirical analyses using the same framework benefitting from each other in the future.

A concern, discussed throughout the literature on vertical product differentiation, is the finding of symmetric equilibrium patterns in which a single firm offers multiple product variants with equal prices and qualities. For the deterministic framework, Mussa and Rosen (1978) and Cheng et al. (2011) show that fully differentiated patterns of product differentiation exist, whereas for the more general random utility framework we are the first to show that such fully differentiated patterns exist. However, in contrast to the deterministic framework, within the random utility framework the existence of fully differentiated patterns of vertical product differentiation is conditional on the relative importance of the observed heterogeneity compared with the unobserved heterogeneity in utility amongst consumers. We show that unobserved inter- and intra product heterogeneity, $\mu_{2}$, should be small relative to the observed dispersion of willingness to pay for quality, $\bar{\theta}-\underline{\theta}$, in order to find asymmetric equilibrium patterns.

We conclude that the relative welfare loss of the monopoly compared with the social optimal outcome is constant for both the deterministic and random utility model. The monopoly welfare equals 0.75 times the welfare obtained in the social optimum. The relative welfare loss is independent of observed heterogeneity in the sensitivity for quality. Furthermore, it does not depend on unobserved heterogeneity in the demand for product variants, neither in unobserved heterogeneity in the demand for the product at all, as represented by the scale parameters $\mu_{2}$ and $\mu_{1}$ respectively. The scale 
parameters have the same effect on the profit function to be maximised by the monopoly as the welfare function maximised by the social planner.

Based on our study we can sketch two different directions to extend this research and our understanding of multi-product differentiation. Firstly, and most importantly, the results of this study should be expanded to cover for other market structures, such as duopolistic and oligopolistic multiproduct markets. Although we conjecture, based on the article by Cheng et al. (2011), that the results may hold for different market structures, the inclusion of strategic interaction between firms using a random utility framework is challenging.

Next, although the literature tends to study horizontal and vertical product differentiation separately, an effort should be made to combine both sources of product differentiation, because it is also the combination of both playing a role in many industries. For the random utility framework, Anderson et al. (1992) already provide analyses, mostly focussing on horizontal differentiation, into this direction. 


\section{Appendix A.}

Here we show the first order conditions with respect to prices and qualities for the random utility model. Please keep in mind that the complete set of first order conditions with respect to a decision variable contains $n$ similar expressions. Taking the derivative with respect to prices of the profit function yields:

$$
\frac{\partial \pi_{m}}{\partial p_{i}}=\sum_{t}\left(\mathrm{P}_{i m, t}-\alpha \psi_{i} \mathrm{P}_{i m, t}\left(\frac{1-\mathrm{P}_{i \mid m, t}}{\mu_{2}}+\frac{\mathrm{P}_{i \mid m, t}\left(1-\mathrm{P}_{m, t}\right)}{\mu_{1}}\right)+\alpha\left(\mathrm{P}_{i m, t}\left(\frac{1}{\mu_{2}}-\frac{1-\mathrm{P}_{m, t}}{\mu_{1}}\right) \sum_{j=1, j \neq i}^{n} \psi_{j} \mathrm{P}_{j \mid m, t}\right)\right)
$$

And with respect to qualities yields:

$$
\frac{\partial \pi_{m}}{\partial q_{i}}=\sum_{t}\left(-q_{i} \mathrm{P}_{i m, t}+\theta_{t} \psi_{i} \mathrm{P}_{i m, t}\left(\frac{1-\mathrm{P}_{i \mid m, t}}{\mu_{2}}+\frac{\mathrm{P}_{i \mid m, t}\left(1-\mathrm{P}_{m, t}\right)}{\mu_{1}}\right)-\theta_{t}\left(\mathrm{P}_{i m, t}\left(\frac{1}{\mu_{2}}-\frac{1-\mathrm{P}_{m, t}}{\mu_{1}}\right) \sum_{j=1, j \neq i}^{n} \psi_{j} \mathrm{P}_{j \mid m, t}\right)\right)
$$

with $\psi_{i}=p_{i}-\frac{q_{i}^{2}}{2}$ for $i \in n$. Solving $\frac{\partial \pi_{m}}{\partial p_{i}}=0$ and $\frac{\partial \pi_{m}}{\partial q_{i}} \stackrel{!}{=} 0$ for $\psi_{i}$, the mark-up for product variant $i$, results into two expressions for this mark-up, Eq. (A.3) and Eq. (A.4) respectively:

$$
\psi_{i}=\frac{\frac{\mu_{2}}{\alpha} \sum_{t}\left(\mathrm{P}_{i m, t}\right)+\sum_{t}\left(\mathrm{P}_{i m, t}\left(1-\frac{\mu_{2}}{\mu_{1}}\left(1-\mathrm{P}_{m, t}\right)\right) \sum_{j=1, j \neq i}^{n} \psi_{j} \mathrm{P}_{j \mid m, t}\right)}{\sum_{t} \mathrm{P}_{i m, t}\left(\left(1-\mathrm{P}_{i \mid m, t}\right)+\frac{\mu_{2}}{\mu_{1}}\left(1-\mathrm{P}_{m, t}\right) \mathrm{P}_{i \mid m, t}\right)},
$$

and 


$$
\psi_{i}=\frac{\mu_{2} q_{i} \sum_{t}\left(\mathrm{P}_{i m, t}\right)+\sum_{t}\left(\theta_{t} \mathrm{P}_{i m, t}\left(1-\frac{\mu_{2}}{\mu_{1}}\left(1-\mathrm{P}_{m, t}\right)\right) \sum_{j=1, j \neq i}^{n} \psi_{j} \mathrm{P}_{j \mid m, t}\right)}{\sum_{t} \theta_{t} \mathrm{P}_{i m, t}\left(\left(1-\mathrm{P}_{i \mid m, t}\right)+\frac{\mu_{2}}{\mu_{1}}\left(1-\mathrm{P}_{m, t}\right) \mathrm{P}_{i \mid m, t}\right)} .
$$

The optimal prices and qualities follow from equating the right hand sides of both Eq. (A.3) and Eq. (A.4) to each other. If we assume only one type of consumers, $t^{*}$, we are back in the original case as shown by Anderson et al. (1992, page 251):

$$
\psi_{i}=\frac{\frac{\mu_{2}}{\alpha}+\left(1-\frac{\mu_{2}}{\mu_{1}}\left(1-\mathrm{P}_{m}\right)\right) \sum_{j=1, j \neq i}^{n} \psi_{j} \mathrm{P}_{j \mid m}}{\frac{\mu_{2}}{\mu_{1}}\left(1-\mathrm{P}_{m}\right) \mathrm{P}_{i \mid m}+\left(1-\mathrm{P}_{i \mid m}\right)},
$$

Employing the same assumption for Eq. (A4), we get the second expression for $\psi_{i}$ :

$$
\psi_{i}=\frac{\frac{\mu_{2} q_{i}}{\theta_{t^{*}}}+\left(1-\frac{\mu_{2}}{\mu_{1}}\left(1-\mathrm{P}_{m}\right)\right) \sum_{j=1, j \neq i}^{n} \psi_{j} \mathrm{P}_{j \mid m}}{\frac{\mu_{2}}{\mu_{1}}\left(1-\mathrm{P}_{m}\right) \mathrm{P}_{i \mid m}+\left(1-\mathrm{P}_{i \mid m}\right)} .
$$

By equating Eq. (A5) and Eq. (A6) we can now find a familiar and consistent expression for the optimal quality:

$$
\frac{\frac{\mu_{2}}{\alpha}+\left(1-\frac{\mu_{2}}{\mu_{1}}\left(1-\mathrm{P}_{m}\right)\right) \sum_{j=1, j \neq i}^{n} \psi_{j} \mathrm{P}_{j \mid m}}{\frac{\mu_{2}}{\mu_{1}}\left(1-\mathrm{P}_{m}\right) \mathrm{P}_{i \mid m}+\left(1-\mathrm{P}_{i \mid m}\right)}=\frac{\frac{\mu_{2} q_{i}}{\theta_{t^{*}}}+\left(1-\frac{\mu_{2}}{\mu_{1}}\left(1-\mathrm{P}_{m}\right)\right) \sum_{j=1, j \neq i}^{n} \psi_{j} \mathrm{P}_{j \mid m}}{\frac{\mu_{2}}{\mu_{1}}\left(1-\mathrm{P}_{m}\right) \mathrm{P}_{i \mid m}+\left(1-\mathrm{P}_{i \mid m}\right)}
$$


Multiplying both sides with $\frac{\mu_{2}}{\mu_{1}}\left(1-\mathrm{P}_{m}\right) \mathrm{P}_{i \mid m}+\left(1-\mathrm{P}_{i \mid m}\right)$, subtracting $\left(1-\frac{\mu_{2}}{\mu_{1}}\left(1-\mathrm{P}_{m}\right)\right) \sum_{j=1, j \neq i}^{n} \psi_{j} \mathrm{P}_{j \mid m}$ from both sides and dividing both sides by $\mu_{2}$ yields:

$$
\frac{1}{\alpha}=\frac{q_{i}}{\theta_{t}}
$$

This expression implies that the optimal quality in case only one consumer group exists, is equal to the willingness to pay for quality expressed in monetary terms because it is multiplied by the reciprocal of the price sensitivity. 


\section{Appendix B.}

\begin{tabular}{|c|c|c|c|c|c|c|c|c|c|c|c|c|}
\hline & \multicolumn{3}{|c|}{ Deterministic } & \multicolumn{9}{|c|}{ Random Utility } \\
\hline & \multirow[b]{2}{*}{$\bar{\theta}=1$} & \multirow[b]{2}{*}{$\bar{\theta}=2$} & \multirow[b]{2}{*}{$\bar{\theta}=5$} & \multicolumn{3}{|c|}{$\mu_{2}=0.1$} & \multicolumn{3}{|c|}{$\mu_{2}=0.5$} & \multicolumn{3}{|c|}{$\mu_{2}=0.9$} \\
\hline & & & & $\bar{\theta}=1$ & $\bar{\theta}=2$ & $\bar{\theta}=5$ & $\bar{\theta}=1$ & $\bar{\theta}=2$ & $\bar{\theta}=5$ & $\bar{\theta}=1$ & $\bar{\theta}=2$ & $\bar{\theta}=5$ \\
\hline$p_{1}$ & 0.32 & 1.28 & 8.00 & 0.14 & 1.21 & 7.63 & 0.14 & 0.62 & 7.55 & 0.14 & 0.60 & 7.22 \\
\hline$p_{2}$ & 0.08 & 0.32 & 2.00 & 0.14 & 0.17 & 1.45 & 0.14 & 0.62 & 1.61 & 0.14 & 0.60 & 2.11 \\
\hline$q_{1}$ & 0.80 & 1.60 & 4.00 & 0.53 & 1.55 & 3.91 & 0.52 & 1.11 & 3.88 & 0.51 & 1.09 & 3.80 \\
\hline$q_{2}$ & 0.40 & 0.80 & 2.00 & 0.53 & 0.58 & 1.71 & 0.52 & 1.11 & 1.79 & 0.51 & 1.09 & 2.05 \\
\hline market share $_{1}$ & 0.40 & 0.40 & 0.40 & 0.27 & 0.35 & 0.44 & 0.31 & 0.34 & 0.43 & 0.34 & 0.37 & 0.41 \\
\hline market share $_{2}$ & 0.40 & 0.40 & 0.40 & 0.27 & 0.29 & 0.37 & 0.31 & 0.34 & 0.37 & 0.34 & 0.37 & 0.38 \\
\hline market share $_{m}$ & 0.80 & 0.80 & 0.80 & 0.55 & 0.64 & 0.81 & 0.62 & 0.68 & 0.80 & 0.68 & 0.74 & 0.79 \\
\hline profit $_{m}$ & 0 & 0 & 0 & 0 & 0 & 0 & 0 & 0 & 0 & 0 & 0 & 0 \\
\hline$C S_{m}$ & 0.04 & 0.16 & 1.00 & 0.28 & 0.38 & 1.15 & 0.34 & 0.42 & 1.16 & 0.39 & 0.48 & 1.16 \\
\hline$C S_{0}$ & 0.16 & 0.64 & 4.00 & 0.80 & 1.10 & 4.18 & 0.96 & 1.24 & 4.19 & 1.14 & 1.44 & 4.30 \\
\hline$W_{m}$ & 0.12 & 0.48 & 3.00 & 0.61 & 0.85 & 3.18 & 0.73 & 0.96 & 3.20 & 0.88 & 1.11 & 3.24 \\
\hline$W_{o}$ & 0.16 & 0.64 & 4.00 & 0.80 & 1.10 & 4.18 & 0.96 & 1.24 & 4.19 & 1.14 & 1.44 & 4.30 \\
\hline$W_{m} / W_{o}$ & 0.75 & 0.75 & 0.75 & 0.75 & 0.77 & 0.76 & 0.76 & 0.77 & 0.76 & 0.77 & 0.77 & 0.75 \\
\hline
\end{tabular}

Table 3 Random utility model and deterministic model social optimal equilibriums, $n=2, \mu_{1}=1, \alpha=1$. 


\begin{tabular}{|c|c|c|c|c|c|c|c|c|c|c|c|c|}
\hline & \multicolumn{3}{|c|}{ Deterministic } & \multicolumn{9}{|c|}{ Random Utility } \\
\hline & \multirow[b]{2}{*}{$\bar{\theta}=1$} & \multirow[b]{2}{*}{$\bar{\theta}=2$} & \multirow[b]{2}{*}{$\bar{\theta}=5$} & \multicolumn{3}{|c|}{$\mu_{2}=0.1$} & \multicolumn{3}{|c|}{$\mu_{2}=0.5$} & \multicolumn{3}{|c|}{$\mu_{2}=0.9$} \\
\hline & & & & $\bar{\theta}=1$ & $\bar{\theta}=2$ & $\bar{\theta}=5$ & $\bar{\theta}=1$ & $\bar{\theta}=2$ & $\bar{\theta}=5$ & $\bar{\theta}=1$ & $\bar{\theta}=2$ & $\bar{\theta}=5$ \\
\hline$p_{1}$ & 0.41 & 1.65 & 10.33 & 0.13 & 1.24 & 10.17 & 0.13 & 0.58 & 8.08 & 0.13 & 0.55 & 6.50 \\
\hline$p_{2}$ & 0.26 & 1.06 & 6.61 & 0.13 & 1.24 & 6.54 & 0.13 & 0.58 & 8.08 & 0.13 & 0.55 & 6.50 \\
\hline$p_{3}$ & 0.15 & 0.60 & 3.72 & 0.13 & 0.90 & 3.69 & 0.13 & 0.58 & 4.01 & 0.13 & 0.55 & 6.50 \\
\hline$p_{4}$ & 0.07 & 0.26 & 1.65 & 0.13 & 0.14 & 1.57 & 0.13 & 0.58 & 1.88 & 0.13 & 0.55 & 1.17 \\
\hline$p_{5}$ & 0.02 & 0.07 & 0.41 & 0.13 & 0.14 & 0.22 & 0.13 & 0.58 & 0.57 & 0.13 & 0.55 & 1.17 \\
\hline$q_{1}$ & 0.91 & 1.82 & 4.45 & 0.52 & 1.57 & 4.51 & 0.52 & 1.08 & 4.02 & 0.51 & 1.04 & 3.60 \\
\hline$q_{2}$ & 0.73 & 1.45 & 3.64 & 0.52 & 1.57 & 3.61 & 0.52 & 1.08 & 4.02 & 0.51 & 1.04 & 3.60 \\
\hline$q_{3}$ & 0.55 & 1.09 & 2.73 & 0.52 & 1.34 & 2.71 & 0.52 & 1.08 & 2.83 & 0.51 & 1.04 & 3.60 \\
\hline$q_{4}$ & 0.36 & 0.73 & 1.82 & 0.52 & 0.52 & 1.77 & 0.52 & 1.08 & 1.94 & 0.51 & 1.04 & 1.52 \\
\hline$q_{5}$ & 0.18 & 0.36 & 0.91 & 0.52 & 0.52 & 0.66 & 0.52 & 1.08 & 1.06 & 0.51 & 1.04 & 1.52 \\
\hline market share $_{1}$ & 0.18 & 0.18 & 0.18 & 0.11 & 0.13 & 0.19 & 0.14 & 0.15 & 0.17 & 0.16 & 0.17 & 0.18 \\
\hline market share $_{2}$ & 0.18 & 0.18 & 0.18 & 0.11 & 0.13 & 0.18 & 0.14 & 0.15 & 0.17 & 0.16 & 0.17 & 0.18 \\
\hline market share $_{3}$ & 0.18 & 0.18 & 0.18 & 0.11 & 0.13 & 0.18 & 0.14 & 0.15 & 0.17 & 0.16 & 0.17 & 0.18 \\
\hline market share $_{4}$ & 0.18 & 0.18 & 0.18 & 0.11 & 0.13 & 0.17 & 0.14 & 0.15 & 0.17 & 0.16 & 0.17 & 0.17 \\
\hline market share $_{5}$ & 0.18 & 0.18 & 0.18 & 0.11 & 0.13 & 0.13 & 0.14 & 0.15 & 0.17 & 0.16 & 0.17 & 0.17 \\
\hline market share $_{\mathrm{m}}$ & 0.90 & 0.90 & 0.90 & 0.57 & 0.66 & 0.84 & 0.72 & 0.77 & 0.86 & 0.83 & 0.86 & 0.88 \\
\hline profit $_{\mathrm{m}}$ & 0 & 0 & 0 & 0 & 0 & 0 & 0 & 0 & 0 & 0 & 0 & 0 \\
\hline $\mathrm{CS}_{\mathrm{m}}$ & 0.04 & 0.16 & 1.03 & 0.30 & 0.40 & 1.20 & 0.43 & 0.53 & 1.27 & 0.59 & 0.68 & 1.38 \\
\hline $\mathrm{CS}_{\mathrm{o}}$ & 0.16 & 0.66 & 4.13 & 0.85 & 1.16 & 4.35 & 1.27 & 1.58 & 4.60 & 1.77 & 2.11 & 4.99 \\
\hline $\mathrm{W}_{\mathrm{m}}$ & 0.12 & 0.50 & 3.10 & 0.65 & 0.89 & 3.33 & 0.98 & 1.23 & 3.51 & 1.39 & 1.66 & 3.81 \\
\hline $\mathrm{w}_{\mathrm{o}}$ & 0.16 & 0.66 & 4.13 & 0.85 & 1.16 & 4.35 & 1.27 & 1.58 & 4.60 & 1.77 & 2.11 & 4.99 \\
\hline$W_{m} / W_{o}$ & 0.75 & 0.75 & 0.75 & 0.76 & 0.77 & 0.77 & 0.77 & 0.78 & 0.76 & 0.78 & 0.78 & 0.76 \\
\hline
\end{tabular}

Table 4 Random utility model and deterministic model social optimal equilibriums, $n=5, \mu_{1}=1, \alpha=1$. 
Bibliography

Anderson, S. P., de Palma, A. (1992a) Multiproduct Firms: A Nested Logit Approach, The Journal of Industrial Economics, 40(3), 261-276.

Anderson, S. P., de Palma, A. (1992b) The Logit As a Model of Product Differentiation, Oxford Economic Papers, 44(1), 51-67.

Anderson, S. P., de Palma, A. (2001) Product Diversity in Asymmetric Oligopoly: Is the Quality of Consumer Goods Too Low?, The Journal of Industrial Economics, 49(2), 113-135.

Anderson, S. P., De Palma, A., Thisse, J. F. (1989) Demand for Differentiated Products, Discrete Choice Models, and the Characteristics Approach, The Review of Economic Studies, 56(1), 21-35.

Anderson, S.P., De Palma, A., Thisse, J.F. (1992) Discrete Choice Theory of Product Differentiation. Cambridge, MA: The MIT Press.

Ben-Akiva, M., Lerman, S.R. (1985) Discrete Choice Analysis: Theory and Application. Massachusetts: MIT Press.

Berry, S., Levinsohn, J., Pakes, A. (1995) Automobile Prices in Market Equilibrium, Econometrica, 63(4), 841-890.

Berry, S. T. (1994) Estimating Discrete-Choice Models of Product Differentiation, The RAND Journal of Economics, 25(2), 242-262.

Bonnisseau, J.-M., Lahmandi-Ayed, R. (2006) Vertical Differentiation: Multiproduct Strategy to Face Entry?, B.E.Journal of Theoretical Economics, 6(1), 1-14.

Champsaur, P., Rochet, J. C. (1989) Multiproduct Duopolists, Econometrica, 57(3), 533-557.

Cheng, Y.-L., Peng, S.-K., Tabuchi, T. (2011) Multiproduct Duopoly With Vertical Differentiation, The B.E.Journal of Theoretical Economics, 11(1), 1-27.

Crawford, G. S. Endogenous Product Choice: A Progress Report, International Journal of Industrial Organization,(2012).

Gabszewicz, J. J., Shaked, A., Sutton, J., Thisse, J. F. (1986) Segmenting the Market: The Monopolist's Optimal Product Mix, Journal of Economic Theory, 39(2), 273-289.

Mussa, M., Rosen, S. (1978) Monopoly and Product Quality, Journal of Economic Theory, 18(2), 301-317.

Tirole, J. (1988) The Theory of Industrial Organization. Cambridge, Massachusetts: The MIT Press.

Train, K. (2003) Discrete Choice Methods With Simulation. Cambridge: University Press. 